\title{
DETERMINACIÓN TAXONÓMICA Y REGISTRO DE LA COLECCIÓN «REGIONAL ICGP 156 FIELD WORKSHOP»
}

\author{
Vera Alleman H.
}

\section{RESUMEN}

Se presenta el registro de 29 muestras de rocas sedimentarias y de fósiles del Eoceno, Mioceno, Plioceno y Pleistoceno provenientes de las Formaciones Paracas, Yumaque, Caballas, Pisco y de las Terrazas Marinas de la Costa Sur de las regiones de Paracas, Ica, Ocucaje y Nazca, en las cuales las localidades citadas se extienden desde el Puente Huamaní, la Reserva Nacional de Paracas hasta San Juan de Marcona.

Al lado de madera silicificada, icnofósiles, diatomeas y radiolarios se reporta dentro de los fósiles animales la presencia de gasterópodos, lamelibranquios, crustáceos y vertebrados.

Las rocas cuentan con la presencia de muestras de areniscas petrolíferas y otras areniscas, limonitas, diatomitas, toba, porcelanita y diferentes morfotipos de fosfatos.

Palabras Claves: Colecciones, paleobotánica, icnofósiles, micropaleontología, invertebrados, vertebrados, terciario, pleistoceno, fosfatos, Paracas, Ica, Ocucaje, Nazca.

\section{SUMMARY}

Twenty nine sedimentary rocks and fossils are registered from the Eocene, Miocene, Pliocene and Pleistocene of the Paracas, Yumaque, Caballas y Pisco Formations and the Marine Terraces of Peruvian South Coast area, from Paracas, Ica, Ocucaje and Nazca, localities situated from the Huamani Bridge, through the «Reserva Nacional de Paracas», to San Juan de Marcona.

Silicificated wood, ichnofossils, diatoms and radiolaria and fossil animals are reported with gastropods, pelecypods, cirripeds and vertebrates.

The sediments include petroliferous sandstone and other kinds of sandstones, limonites, diatomites, porcellanites, and different morphotypes of phosphates.

Key Words: Collections, paleobotany, ichnofossils, micropaleontology, invertebrate, vertebrate, tertiary, pleistocene, phosphate, Paracas, Ica, Ocucaje, Nazca.

\footnotetext{
${ }^{1}$ Museo de Historia Natural, Sección de Paleontología, Universidad Ricardo Palma; Facultad de Ciencias Biológicas, Universidad Ricardo Palma; e-mail:valleman@mail.urp.edu.pe
} 


\section{INTRODUCCIÓN}

La cuenca sedimentaria de Pisco constituye un ejemplo para entender ambientes de una sedimentación primaria, efectos de aguas de resurgencia, procesos de diagenesis y sedimentación volcánica. La recolección de muestras se realizó por la autora durante el trabajo de campo efectuado entre el 17 y 24 de Mayo de 1988. Treinte y ocho especialistas de los Estados Unidos de América, de Chile y del Perú estuvieron participando con sus ponencias (R. Dunbar y P. Baker, 1988).

La presente colección es la única registrada. El material no ha sido tratado científicamente y está conservado para futuras investigaciones de especificaciones taxonómicas y litológicas. Varias muestras de rocas fosilíferas se prestan para investigaciones en micropaleontología.

Las muestras y las notas de campo están depositadas en la Sección de Paleontología del Museo de Historia Natural de nuestra Universidad. Se justifica la primicia de la divulgación de nuestra colección como aporte documentario en la perspectiva de la elaboración de proyectos en Paleontología en la Reserva Nacional de Paracas (INRENA, Plan Maestro de la Reserva Nacional de Paracas 2003-2007).

\section{MATERIAL Y MÉTODOS}

El material recolectado consiste en un muestreo de rocas fosilíferas y fósiles recolectados en localidades debidamente ubicadas en diferentes mapas topográficos y geológicos y en secciones estratigráficas. La sedimentología y las faunas asociadas así como todo tipo de datos científicos que pudieron acompañar las muestras están en la Guía de Campo, obra citada (R. Dunbar y P. Baker, 1988).

Las muestras están depositadas en la Sección de Paleontología del Museo de Historia Natural de la Universidad Ricardo Palma, con el nombre de: Colección «Regional IGCP 156 Field Workshop» bajo los códigos de RPE0101 a RPE0129.

\section{DETERMINACIÓN TAXONÓMICA Y REGISTRO}

RPE0101 Turritella paracasensis Rivera, 1957.

1957 Turritella paracasensis Rivera en Rivera, R. Moluscos fósiles de la Formación Paracas, Dpto. de Ica. Bol. Soc. Geol. Perú 32: 174 Lám. I, Fig. 2; Lám. II, Fig. 11.

Localidad: Punta Prieto, base del Cerro Prieto. Bahía Lechuga, Península de Paracas, Dpto. de Ica.

Distribución cronoestratigráfica: Eoceno.

Unidad estratigráfica: Formación Paracas: base.

Observaciones: Arenisca de color D 81, interpretada como resultado de una tempestad (columna R. Wright en obra citada: 172-173.)

RPE0102 Coquina de ostras y de ¿briozoarios?

Localidad: Playa Lagunillas (Yumaque), Paracas, Dpto. de Ica.

Distribución cronoestratigráfica: Eoceno Eoceno Superior.

Unidad litoestratigráfica: Formación Paracas: techo.

Observaciones: Arenisca ligeramente petrolífera, calificada de color marrón por R. Wright y depositada en un ambiente de baja energía (obra citada: 177).

RPE0103 Lamelibranquio y restos orgánicos fosfatados.

Localidad: Playa Las Salinas. Reserva Nacional de Paracas, Dpto. de Ica.

Distribución cronoestratigráfica: Eoceno

Unidad litoestratigráfica: Formación Yumaque, parte superior.

Observaciones: Limonita (mudstone)

RPE0104 Nódulo de fosfato y escamas de pez fosfatadas.

Localidad: Punta Salinas. Reserva Nacional de Paracas, Dpto. de Ica.

Distribución cronoestratigráfica. Eoceno.

Unidad litoestratigráfica: Formación Yumaque.

Observaciones: Porcelanita laminada. 
RPE0105 Icnofósiles: Dolomita con perforaciones por organismos bentónicos.

Localidad: Lomas Cuesta Chilcatay. Carretera Comatrana (Bahía de la Independencia hacia Ica ). Fig. 4.1., pág. 187, obra citada. Reserva Nacional de Paracas, Dpto. de Ica.

Distribución cronoestratigráfica: Oligoceno Superior (?) - Mioceno

Inferior.

Unidad litoestratigráfica: Formación Caballas Inferior.

Observaciones: Las perforaciones alcanzan de 5-10 $\mathrm{cm}$. El diámetro de los tubos varía entre $3-7 \mathrm{~mm}$.

RPE0106 Moldes incompletos de lamelibranquios. Pitar (?)

Localidad: Lomas Cuesta Chilcatay. Carretera Comatrana. Reserva Nacional de Paracas, Dpto. de Ica.

Distribución cronoestratigráfica: Oligoceno Superior (?)-Mioceno Inferior.

Unidad litoestratgráfica: Formación Caballas Inferior

Observaciones: Las capas que contienen estos lamelibranquios están localizadas encima de las dolomitas perforadas y presentan un faciés de aguas profundas del Neógeno Temprano según T. De Vries.

RPE0107 Nódulos de fosfatos.

Localidad: Cerro Blanco. Ocucaje, Dpto. de Ica.

Distribución cronoestratigráfica: Mioceno.

Unidad litoestratgráfica: Formación Pisco.

Observaciones: Se encuentran al pie del Cerro, en el piso, caídos por erosión de la parte mediana del Cerro Blanco.

RPE0108 Molde interno de lamelibranquio.

Localidad: Cerro Blanco. Ocucaje, Dpto. de Ica.

Distribución cronoestratigráfica: Mioceno.

Unidad litoestratigráfica: Formación Pisco.

Observaciones: Se nota que el lamelibranquio perdió totalmente la materia de su esqueleto. Estaba ubicado en la base del Cerro Blanco.
RPE0109 «Balanus» y restos de lamelibranquios.

Localidad: Cerro Blanco. Ocucaje, Dpto. de Ica.

Distribución cronoestratigráfica: Mioceno. Unidad litoestratigráfica: Formación Pisco.

RPE0110 Gasterópodo, restos fosilíferos y depósitos de fosfatos en forma amorfa y en forma de nódulos.

Localidad: Cerro Blanco. Ocucaje, Dpto. de Ica.

Distribución cronoestratigráfica: Mioceno. Unidad litoestratigráfica: Formación Pisco.

Observaciones: Se observa el gasterópodo cuyo esqueleto se conservó, probablemente protegido por las capas de nódulos fosfáticos y, en la parte inferior está ubicada una capa de depósito de fosfato de color negro.

RPE0111 Veneridae.

Localidad: Cerro Blanco. Ocucaje, Dpto. de Ica.

Distribución cronoestratigráfica: Mioceno. Unidad litoestratigráfica: Formación Pisco.

Observaciones: Ubicado en un nivel encima de la muestra anterior, no todos los moluscos perdieron el esqueleto.

RPE0112 Lamelibranquios y balanos.

Localidad: Cerro Blanco. Ocucaje, Dpto. de Ica.

Distribución cronoestratigráfica: Mioceno.

Unidad litoestratigráfica: Formación Pisco.

RPE113 Diatomita laminada con arenisca.

Localidad: Fundo Desbarrancado, Dpto. de Ica.

Distribución cronoestratigráfica: Eoceno Superior.

Unidad litoestratigráfica: Formación Yumaque

Observaciones: vea obra citada: foto pág. 62.

RPE0114 Muestra de diatomita

Localidad: Fundo Desbarrancado, Dpto. de Ica.

Distribución cronoestratigráfica: Eoceno Superior.

Unidad litoestratigráfica: Formación Yumaque

RPE0115 Porcelanita con radiolarios. 
Localidad: Fundo Desbarrancado, Dpto. de Ica.

Distribución cronoestratigráfica: Eoceno Superior.

Unidad litoestratigráfica: Formación Yumaque

Observaciones: datados de hace 39-37 ma.

RPE0116 Vértebras de pez y maderas fosilizadas.

Localidad: Quebrada del Gramonal (Cañon del Diablo). Ocucaje, Dpto. de Ica.

Distribución cronoestratigráfica: Mioceno.

Unidad litoestratigráfica: Formación Pisco.

RPE0117 Dientes de seláceos y

gasterópodo.

Localidad: Cerro Sichuito, Dpto. de Ica.

Distribución cronoestratigráfica: Mioceno.

Unidad litoestratigráfica: Formación Pisco.

RPE0118 Nódulos de fosfatos

Localidad: Cerro Fosfato, camino al Cerro Huaracangana, Dpto de Ica.

Distribución cronoestratigráfica: Mioceno.

Unidad litoestratigráfica: Formación Pisco.

RPE0119 Veneridae.

Localidad: Hacienda Tunga. Región de Nazca, Dpto. de Ica.

Distribución cronoestratigráfica: Plioceno.

Unidad litoestratigráfica: Formación Pisco Superior.

Observaciones: muestras recolectadas por casualidad al borde del camino durante una parada accidental de la movilidad.

RPE0120 Veneridae.

Localidad: Hacienda Tunga. Región de Nazca, Dpto. de Ica.

Distribución cronoestratigráfica: Plioceno.

Unidad litoestratigráfica: Formación Pisco Superior.

RPE0121 Veneridae.

Localidad: Hacienda Tunga. Región de Nazca, Dpto. de Ica.

Distribución cronoestratigráfica: Plioceno.

Unidad litoestratigráfica: Formación Pisco Superior.

RPE0122 Veneridae.

Localidad: Hacienda Tunga. Región de Nazca, Dpto. de Ica.
Distribución cronoestratigráfica: Plioceno.

Unidad litoestratigráfica: Formación Pisco Superior.

RPE0123 Gasterópodo

Localidad: Quebrada Huaracangana, región de Nazca, Dpto. de Ica.

Distribución cronoestratigráfica: Mioceno Tardio-Plioceno.

Unidad litoestratigráfica: Formación Pisco Superior.

RPE0124 Pomita volcánica.

Localidad: Quebrada Huaracangana, región de Nazca, Dpto. de Ica.

Distribución cronoestratigráfica: Mioceno Mediano.

Unidad litoestratigráfica: Formación Pisco.

RPE0125 Gasterópodo

Localidad: Quebrada Huaracangana, región de Nazca, Dpto. de Ica.

Distribución cronoestratigráfica: Mioceno Mediano.

Unidad litoestratigráfica: Formación Pisco

RPE0126 Toba riolítica.

Localidad: Carretera hacia las minas de San Juan de Marcona, Dpto. de Ica.

Distribución cronoestratigráfica: Desconocida.

Unidad litoestraitgráfica: Desconocida.

Observaciones: De lejos podría confundirse con diatomita, por el color blanquecino de la roca.

RPE0127 Muestreo de moluscos lamelibranquios y gasterópodos.

Localidad: Cercanía del aeropuerto de San Juan de Marcona, Dpto. de Ica.

Distribución cronoestratigráfica: Pleistoceno Superior.

Unidad litoestratigráfica: Terrazas Marinas.

RPE0128 Diente de Isurus sp.

Localidad: Cerro Monte Caucato.

Distribución cronoestratigráfica: Mioceno.

Unidad litoestratigráfica: Formación Pisco.

RPE0129 Diatomita y restos de pez.

Localidad: Cerro Monte Caucato.

Distribución cronoestratigráfica: Mioceno.

Unidad litoestratigráfica: Formación Pisco. 


\section{CONCLUSIONES}

La región explorada tiene altos potenciales de investigación paleontológica, de didáctica y turística, especialmente en el área de la Reserva Nacional de Paracas, donde además de las localidades citadas del Cenozoico, cuenta con el Paleozoico de $\ll$ La Mina», localidad típica de gran biodiversidad y de varios ambientes deposicionales con numerosos taxones de géneros y especies nuevos de la denominada zona paleoflorística Paracas.

Es recomendable de desarrollar las investigaciones originales en paleobotánica, micropaleontología y macropaleontología de invertebrados y vertebrados. Se necesita reconstruir las colecciones tipos de moluscos del Cenozoico y realizar un tratamiento taxonómico actualizado a los taxones reportados.

Se justifica la realización de colecciones de exhibición en un museo de sitio ubicado en la Reserva Nacional de Paracas para la divulgación de las riquezas paleontológicas de la región con visión educativa a la población.

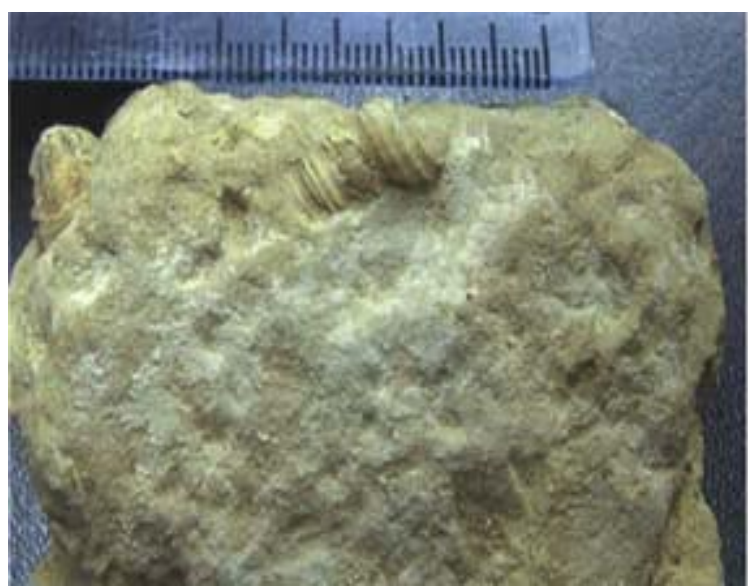

Fig.1: RPE0101 Turritella paracasensis Rivera, 1957
La región presenta una gran belleza natural y ofrece acceso de desarrollo turística de visita a diferentes localidades fosilíferas.

\section{LITERATURA CITADA}

R. DUNBAR y P. BAKER 1988 Cenozoic Geology of the Pisco Basin. A Guidebook to accompany a Regional IGCP 156 Field Workshop : «Genesis of Cenozoic Phophorites and Associated Organic-rich Sediments: Peruvian Continental Margin.». Lima, Perú.253 pp.

RIVERA, R. 1957 Moluscos fósiles de la Formación Paracas, Dpto. de Ica. Bol. Soc. Geol. Perú 32: 165-219.

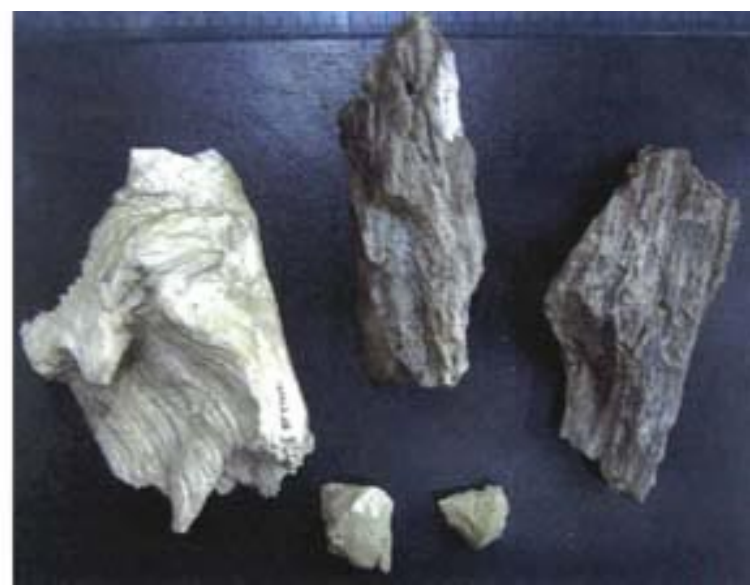

Fig. 2: RPE0116 Vértebras de pez y manchas fosilizadas

Fig. 2: RPE0116 Vértebras de pez y maderas fosilizadas 